
\title{
RETRATO DA JUDICIALIZAÇÃo DA SAÚDE NO
Munalícílo DE SÃO PAULO ENTRE 2017 E SETEMBRO DE $2018 \quad E$ OS PRINCIPAIS RESULTADOS OBTIDOS PELAS AÇÕES ADOTADAS

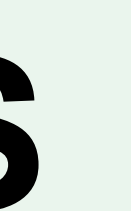

Paulo Kron Psanquevich- Rafael Augusto Galvani Fraga Moreira INTRODUÇÃO

paulokron@prefeitura.sp.gov.br

Instituição:

Secretaria Municipal da Saúde

O direito à saúde vem sendo abarcado através de decisões judiciais que determinam ao poder público a obrigação de fornecer medicamentos, insumos, equipamentos, consultas, exames, cirurgias, transferências e tratamentos aos munícipes, os quais não estariam sendo atendidos em plenitude, em seus direitos, pelos gestores públicos. Este fenômeno é conhecido como "judicialização da saúde", ou seja, o pape determinante do Poder Judiciário diante das ações judiciais que lhe são dirigidas para o fornecimento de medicamentos e/ou tratamentos, frequentemente não contemplados pelo SUS. A Constituição Federal de 1988, que trouxe a saúde como direito social de todos os brasileiros, dependente de políticas públicas de Estado (art. 196), criou o Sistema Único de Saúde (SUS) para garantia das ações e serviços assistenciais universais, igualitários e integrais (art. 198), acabando por propiciar, em pouco tempo, o aumento geração de significativo impacto orçamentário. Diante desta perspectiva, no Município de São Paulo, nos anos de 2017 e 2018, teve início o reforço da estrutura administrativa da Secretaria Municipal de Saúde (SMS) no sentido do enfrentamento desta realidade, em especial, com a implementação e incremento do setor técnico e jurídico especializado nesta temática, o que trouxe mais subsídios para a defesa da as referidas ac̃̃es adotas, no presente de recursos públicos em ações individuais nas situações amostrais analisadas, bem como na redução de gastos totais em compras judiciais para que os mesmos fossem aplicados nos programas de saúde pública do SUS paulistano. Este estudo é um retrato do panorama da Judicialização da Saúde no Município de São Paulo e os principais resultados obtidos por este trabalho.

\section{OBJETIVO}

Apresentação da Consolidação dos dados em relação à Judicialização da Saúde no Município de São Paulo e das estratégias adotadas visando o enfrentamento da questão.

METODOLOGIA

- Tipo de Estudo: Levantamento documental, descritivo, retrospectivo com análise quantitativa amostral. - Local do estudo: Gabinete da SMS.

III- Amostra: a) Retrato da Judicialização da Saúde no Município de São Paulo entre 01/2017 e 09/2018; b) Medicamentos de alto custo no ano de 2017; c) Ação Civil Pública- Pessoa com Deficiência- Fornecimento de prótese auditiva, suropodálica e cadeira de rodas; d) Recurso repetitivo- Resp- STJ- Tema 106Canabidiol; e) Home Care ; f) Medicamento Nusinersen e Atrofia Muscular Espinhal

V- Instrumento de Coleta de Dados: a) Banco de Pareceres Técnicos da Coordenação Técnica em Ações Judiciais da SMS (CTAJ); b) Banco de dados da PGM; c) Pesquisa no site da Imprensa Oficial do Estado de São Paulo; d) Pesquisa de preços de mercado de medicamentos pela internet.

RESULTADOS

a) Retrato da Judicialização da Saúde no Município de São Paulo entre 01/2017 e 09/2018 e respectivas ações adotadas para o enfrentamento das demandas judiciais :

1) Ações adotadas pela SMS para enfrentamento da Judicialização da Saúde: Diante do desafio ao tribunais de justiça do país a formac̃ão dos núcleos de apoio técnicocional de Justiça, que estipulou aos do ano de 2017, reestruturou as áreas jurídicas e técnicas que lidavam com as demandas judiciais, sendo criada a Coordenação Técnica em Aç̃̃es Judiciais (CTAJ) formada por médicos e farmacêutico e o Departamento de Ações Judiciais com incremento de profissionais do direito. Desta feita e em consonância com a literatura referenciada, a equipe técnica formada por SMS, tem emitido e aprimorado pareceres técnicos que subsidiaram de maneira mais acurada a defesa da municipalidade de São Paulo e à Justiça Pública, em especial, com análise da compatibilidade entre a patologia e o tratamento pleiteado com as políticas públicas e literatura médica, além do acompanhamento de audiências judiciais/perícia técnica e, por consequência, uma melhor elucidação das variáveis clínicas e terapêuticas de cada ação judicial analisada.

2) Retrato da Judicialização da Saúde no Município de São Paulo entre 01/2017 e 09/2018: O município de São Paulo contava com 4.190 ações até setembro de 2018, o que representou 0,032\% da população paulistana - 01 processo a cada 3.125 habitantes (Fonte: PGM-JUD3 e JUD 4- Setembro/2018). Destas ações, 3.955 ou $94,4 \%$ do total são tipificadas como "Requisição de Medicamento e/ou Tratamento" e 235 ações $(5,6 \%)$ são relativas à Indenização por Danos Morais e Materiais por Suposto Erro Médico. No município de São Paulo, das ações tipificadas como "Requisição de Medicamento e/ou Tratamento", 61\% se referem a medicamentos, materiais médico-hospitalares ou insumos. O restante de $39 \%$ referem-se a cirurgias, consultas, tratamentos, internações e transferências para outras unidades de maior complexidade e/ou UTI. O gráfico a seguir demonstra a tipificação das solicitações: 44\% são de medicamentos, $17 \%$ insumos, $16 \%$ de tratamentos médicos, 13\% para cirurgias e $10 \%$ outros.(Figura 1 ). Em relação a processos judiciais novos, foi observada uma discreta redução no aumento das mesmas, iniciando no final de 2016 e início de 2017. Da totalidade das ações judiciais dirigidas ao Município de São Paulo, 88\% foram provenientes da Justiça Estadual de São Paulo (TJ-SP) e 12\% do restante da Justiça Federal em São Paulo (TRF-3). Já, em processos oriundos da Justiça Estadual, observamos que $70 \%$ das ações foram originárias das Varas de Fazenda Pública e 30\% do restante em Varas da Infância e da Juventude. Em relação ao gasto total das compras de medicamentos e itens pela municipalidade de São Paulo, o quadro a seguir identificou queda de cerca de $25 \%$ de 2016 para 2017 (Figura 2) b) Medicamentos de alto custo no ano de 2017: Em relação aos medicamentos de alto custo destacadas na figura 3, com o montante potencial de gasto de quase $\mathrm{R} \$ 13,5$ milhões de reais, porém tais gastos foram evitados, mediante alternativas terapêuticas disponíveis no SUS, pareceres técnicos que melhor subsidiaram a PGM e a Justiça Pública e a parceria com a Secretaria Estadual de Saúde, o que permitiu à SMS a continuidade da aplicação de recursos nos programas de saúde do SUS paulistano. c) Ação Civil Pública- Pessoa com Deficiência- Fornecimento de prótese auditiva, suropodálica e cadeira referidos maptrais médico hospitalares. O valor da ação conigido em 09/2018 chegou a R\$ 1,35 bihôes de reais. Após análise e apoio técnico de areas da SMS, foi assinado termo de ajustamento de conduta (TAC) entre a SMS e o Ministerio Público Estadual em novembro de 2017, para fornecimento de prótese auditiva até 06 meses, órteses suropodálicas em até 12 meses e cadeiras de rodas em até 18 meses, o

qual ve
reais.

d) Recurso repetitivo- Resp- STJ- Tema 106- Canabidiol: O Superior Tribunal de Justiça (STJ) concluiu em abril de 2018 o julgamento do recurso repetitivo, que fixou requisitos para que o Poder Judiciário determine o fornecimento de medicamentos fora da listagem do SUS, sendo exigidos nos processos judiciais: 1- Comprovação, por meio de laudo médico fundamentado e circunstanciado da imprescindibilidade ou necessidade do medicamento, assim como da ineficácia, para o tratamento da moléstia, dos fármacos fornecidos pelo SUS; 2 - Incapacidade financeira do paciente de arcar com o custo do medicamento prescrito; e 3 - Existência de registro do medicamento na Anvisa.

Tal recurso tem sido aplicado nos processos judiciais de SMS, com sucesso, no sentido de reverter liminares, especialmente, quanto aos medicamentos sem registro na ANVISA. De abril a setembro de 2018, a SMS recebeu 15 ações judiciais pleiteando o item Canabidiol, que não possui registro na ANVISA. O preço médio de mercado do frasco era de $\mathrm{R} \$ 2,8$ mil reais, sendo que se utilizaria em media 12 frascos por paciente, com gasto potencial de $\mathrm{R} \$ 510,7 \mathrm{~m}$ reais com a totalidade das 15 ações judiciais. Diante da utilização do referido recurso, foi gasto o montante de apenas écnicos que melhor subsidiaram a PGM e a Justiça Pública, foram sugeridas alternativas terapêuticas disponíveis no SUS para os pacientes.

e) Home Care: Em relação à solicitação de Home Care, a SMS recebeu até setembro de 2018, 09 ações judiciais

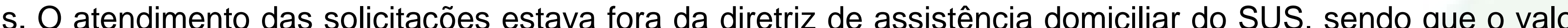
gasto poderia alcançar $R \$ 5,4$ milhões de reais ao ano. Por meio de análise técnica e adequação ao protocolo de assistencia domiciliar do SUS pelas equipes multiprofissionais de atenção domiciliar (EMAD), vinculadas à atenção básica, os pacientes foram devidamente atendidos, sendo que apenas a uma paciente foi disponibilizado home care for dos padrões do SUS, por sentença judicial, com o valor até final de setembro acumulado de R\$153,4 mil reais.

f) Medicamento Nusinersen e Atrofia Muscular Espinhal: Em São Paulo, a atrofia muscular espinhal (AME), doença degenerativa neurológica genética, conta com retaguarda dos serviços da AACD, Escola Paulista de Medicina e Grupo de Doenças Neuromusculares do Ambulatório de Neurologia Infantil do HCFMUSP. Recentemente, foi introduzido medicamento Nusinersen para AME, de altíssimo custo. O preço de mercado é de cerca de $\mathrm{R} \$ 483,5$ mil reais/ampola sendo que o tratamento de 01 ano pode totalizar cerca de R\$5,8 milhões de reais. A SMS recebeu 07 ac̃ões judiciais até setembro de 2018, com a solicitacão deste medicamento, com gasto potencial de R\$40,6 milhões de reais. Após devida informacão clínica, terapêutica e jurídica ao Poder Judiciário, somente 02 destas ações judiciais culminaram com sentença judicial determinando a compra do medicamento, pelo que foram gastos até setembro de 2018 o montante de $\mathrm{R} \$ 3$ milhões de reais. Por meio de pareceres técnicos que melhor subsidiaram a PGM e a Justiça Pública, verificou-se se os pacientes estavam sendo atendidos pela rede de saúde com suporte muscular, neurológico e fisioterápico,

Processos por Objeto de Demanda

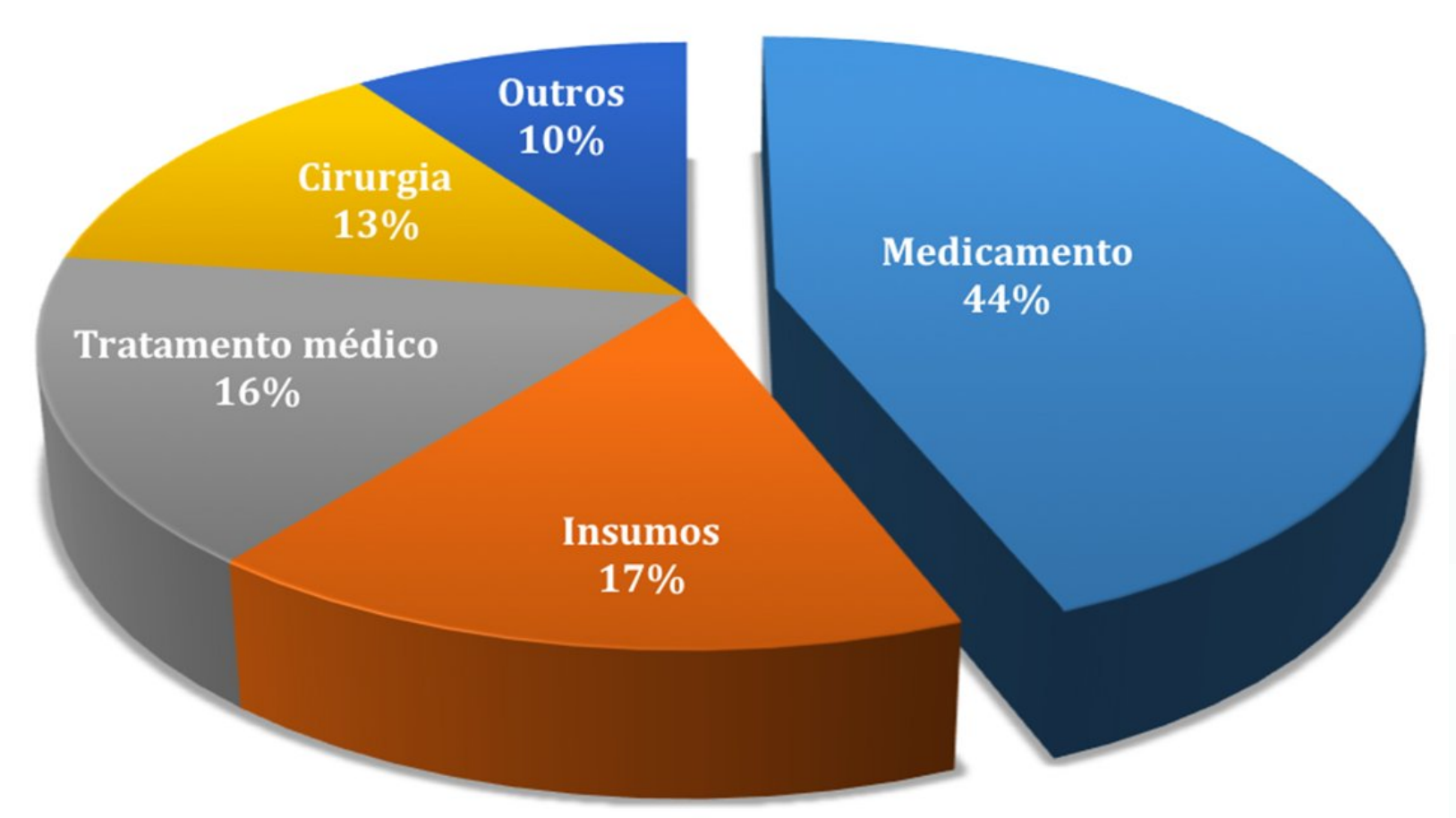

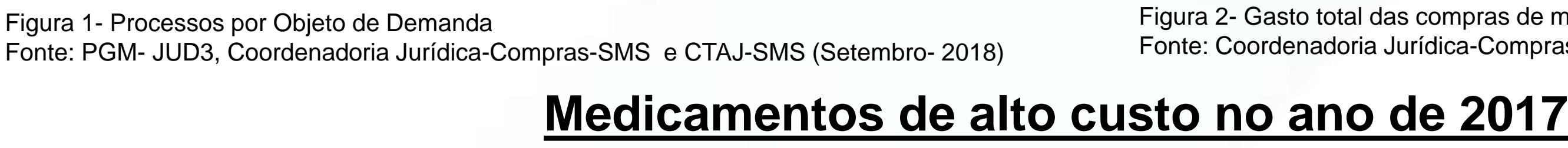

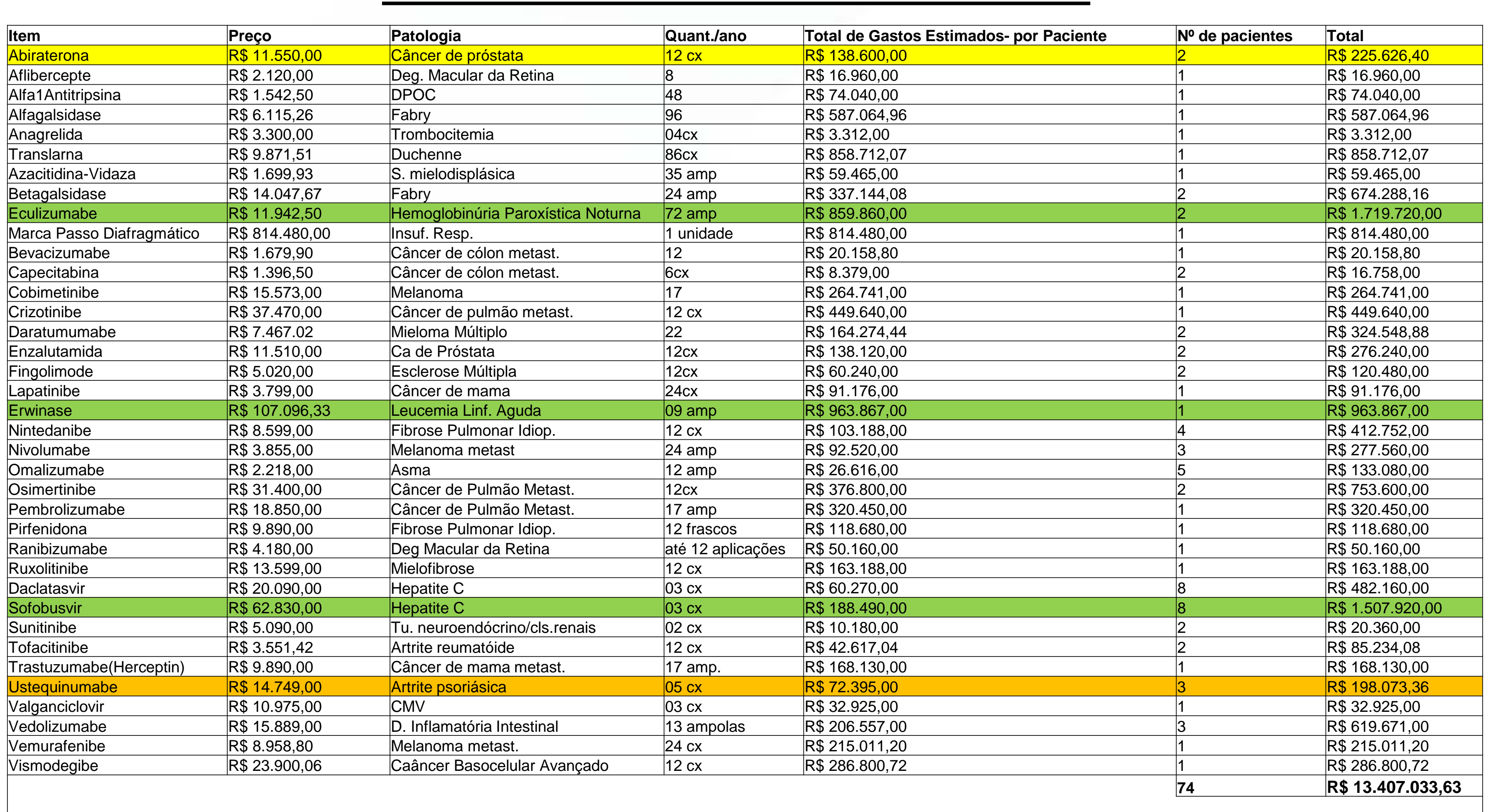

CONCLUSÃO

Com este estudo, observa-se a consolidação dos dados referentes à judicialização da saúde no Município de São Paulo bem como as estratégias adotadas pela municipalidade no enfrentamento da matéria em 2017 e 2018, especialmente com a formação do corpo jurídico e técnico especializado que guardam relação estatística com a redução dos gastos de recursos públicos em açoes individuais nas situações amostrais analisadas, bem como na redução de gastos totais em estudos devem ser realizados para verificar as peculiaridades de cada ação judicial e relação "causa-efeito" com os resultados apresentados neste trabalho.

REFERÊNCIAS

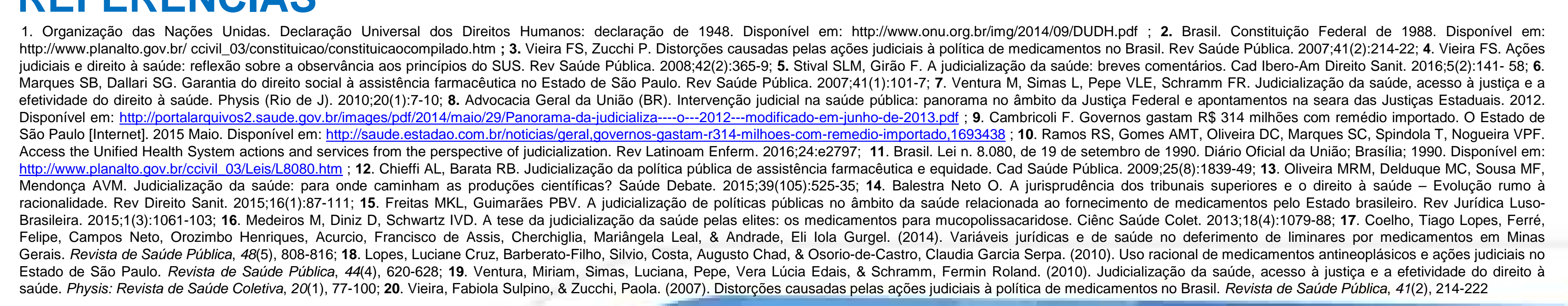

Gasto total das compras de medicamentos

\begin{tabular}{|c|c|}
\hline $\begin{array}{c}\text { Valores gastos em } \\
\text { reais }\end{array}$ & ANO \\
\hline $\mathrm{R} \$ 4.168 .787,09$ & 2017 \\
\hline $\mathrm{R} \$ 5.556 .924,18$ & 2016 \\
\hline $\mathrm{R} \$ 4.633 .005,72$ & 2015 \\
\hline $\mathrm{R} \$ 3.557 .919,48$ & 2014 \\
\hline $\mathrm{R} \$ 3.863 .907,72$ & 2013 \\
\hline
\end{tabular}

Prase

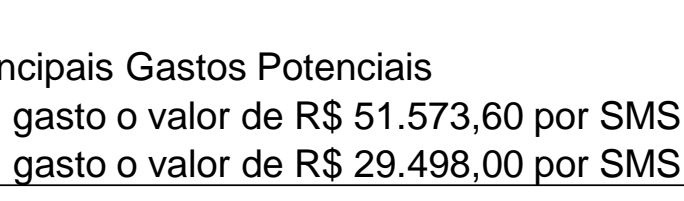

